\title{
Chemical structure of the Earth's mantle defined by fast diffusion elements like helium
}

\author{
Yun Liu ${ }^{1,2}$
}

Received: 4 November 2019/Revised: 4 November 2019/Accepted: 5 November 2019/Published online: 21 November 2019

(C) Science Press and Institute of Geochemistry, CAS and Springer-Verlag GmbH Germany, part of Springer Nature 2019

\begin{abstract}
A theoretical model and numerical simulation (i.e., Zhu et al. 2019) demonstrates that the Earth's lower mantle was intrinsically stratified for helium (He) by thermal diffusion owing to adiabatic temperature gradient in the Earth. This finding helps to explain the two longstanding problems: the helium concentration paradox and the heathelium paradox.
\end{abstract}

Mass-dependent isotope fractionation of helium is believed to be too small to significantly change ${ }^{3} \mathrm{He} /{ }^{4} \mathrm{He}$ isotopic ratios in geological processes, comparing with the change by radiogenic ${ }^{4} \mathrm{He}$ by $\alpha$-particle $\left({ }^{4} \mathrm{He}\right)$ decay of $\mathrm{U}$ and $\mathrm{Th}$. In addition, He isotope fractionation caused by diffusion is expected to be also small, since $D_{3 \mathrm{He}} / D_{4 \mathrm{He}}=1.03$ (Shuster et al. 2004), where $D_{3 \mathrm{He}}$ and $D_{4 \mathrm{He}}$ are diffusion coefficients of ${ }^{3} \mathrm{He}$ and ${ }^{4} \mathrm{He}$, respectively. Thermal diffusion, also called the Soret effect, has been experimentally and theoretically proved to produce significant amount of elemental and isotopic fractionations (Huang et al. 2010; Li and Liu 2015; Richter et al. 2014; Walker and Delong 1982). However, confirmed natural large-scale processes with such effect have not been found, because mass diffusion rate is several orders of magnitude smaller than that of heat diffusion, thus mass diffusion could not achieve much fractionation before temperature gradient or contrast had vanished.

Therefore, mantle convection tends to homogenized any inhomogeneous reservoirs (Kellogg and Turcotte 1987; Ricard 2015), intrinsic adiabatic (convective) temperature

Yun Liu

liuyun@vip.gyig.ac.cn

1 State Key Laboratory of Ore Deposit Geochemistry, Institute of Geochemistry, Chinese Academy of Sciences, Guiyang 550081, China

2 CAS Center for Excellence in Comparative Planetology, Hefei 230026, China gradient produced by convection is totally overlooked to generate any chemical fractionation. However, Zhu et al. (2019) shows that adiabatic temperature gradient can produce elemental and isotopic fractionations of helium in the lower mantle due to sluggish convection compared to fast diffusion of He. This can't repeat itself in the upper mantle owing to faster convection. The highest ${ }^{3} \mathrm{He} /{ }^{4} \mathrm{He}$ isotopic ratios and lowest He contents are located in the lowermost of lower mantle (Fig. 1), a helium stratified state can be maintained. Such unique chemical composition signals can be captured by super plumes which originates from the core-mantle boundary area. This modeling results of $\mathrm{Zhu}$ et al. (2019) therefore can explain the long-standing 'helium concentration paradox'(Anderson 1998) (Fig. 1).

High ${ }^{3} \mathrm{He} /{ }^{4} \mathrm{He}$ ratios in OIBs are often regarded as evidences for an undegassed mantle source sampled by plumes (Kellogg and Turcotte 1990; Kurz et al. 1982; Moreira 2013; Mukhopadhyay and Parai 2019). However, this conventional model can't explain why helium concentrations are several orders of magnitude lower than in MORBs (Anderson 1998). This paradox has led to a longstanding controversy about the chemical structure and dynamics of the Earth's mantle. Although many models have been proposed, such as the predegassing (Hopp and Trieloff 2008) and disequilibrium degassing models (Gonnermann and Mukhopadhyay 2007), the basal magma ocean model (Labrosse et al. 2007), primordial noble gases in the core (Bouhifd et al. 2013; Porcelli and Halliday 2001), residue of melting (Class and Goldstein 2005; Parman et al. 2005), etc., it is still an open issue (Moreira 2013). Zhu and colleagues' models are brand new and physically rational, and do provide some insights to solve this issue.

Interestingly, Zhu and colleagues also claimed that the helium stratified mantle was formed in the early Earth, and 


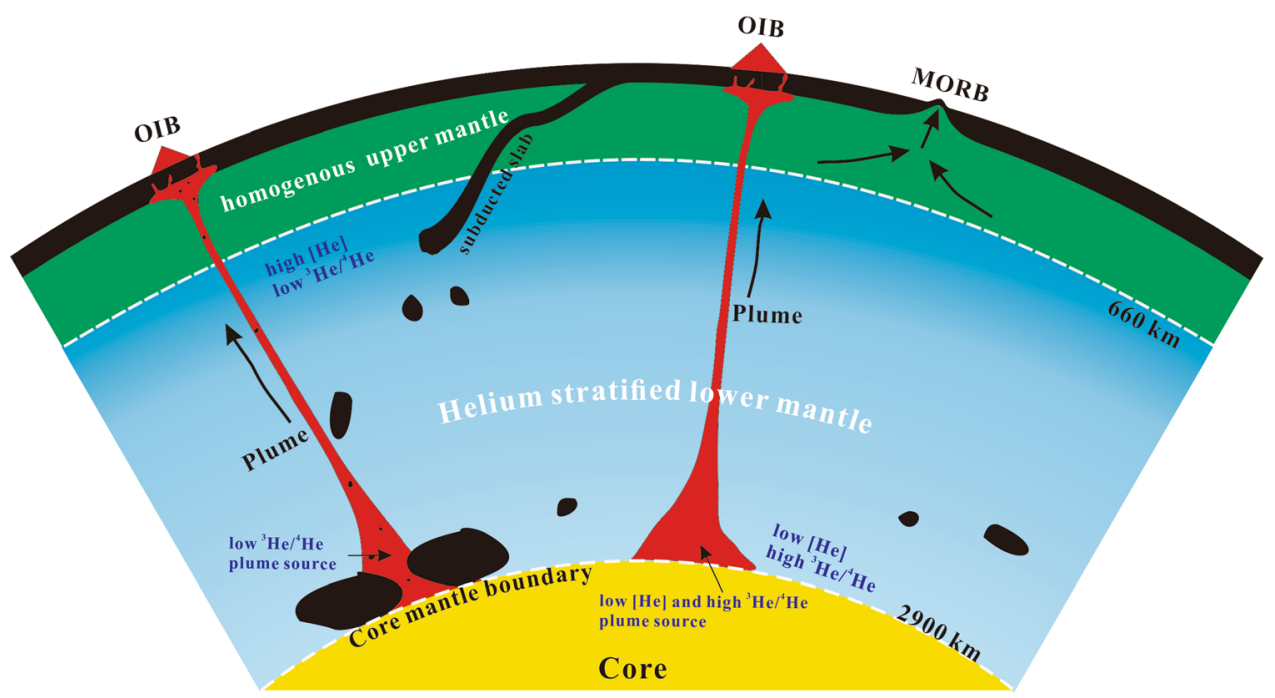

Fig. 1 Diagram demonstrating the intrinsically stratified lower mantle in helium concentration and isotope (Zhu et al. 2019). Helium stratification was established by thermal diffusion due to large temperature contrast across the lower mantle, and can't be removed by the slow convection in the lower mantle. Therefore, super plumes arise from the deepest mantle have highest ${ }^{3} \mathrm{He} /{ }^{4} \mathrm{He}$ isotopic ratios and lowest $\mathrm{He}$ concentrations as observed in OIBs; while some plumes carrying recycled slab will show intermediate values. In contrast, the upper mantle is homogenous in helium because of its vigorous convection, resulting in a narrow range of ${ }^{3} \mathrm{He} /{ }^{4} \mathrm{He}$ ratios

would lead an over-degassed deepest mantle in He due to largest temperature contrast. Thus later evolution of the deepest mantle is helium ingassed process (Zhu et al. 2019). The ingassed helium was probably radiogenic ${ }^{4} \mathrm{He}$. This may help to explain the apparent imbalance of heat and helium released by the Earth, the heat-helium paradox (Onions and Oxburgh 1983). Zhu et al. (2019)'s model is still a hypothesis yet. Future experimental works are desperately needed to provide data about the helium's behavior in the deep mantle.

Nevertheless, the new model by Zhu et al. (2019) will be of value in understanding the chemical structure the Earth's mantle (Fig. 1). Moreover, extrapolation of the new models would suggest that fast diffusion components, such as hydrogen (Demouchy 2010; Hae et al. 2006), would be also enriched in their light isotopes in the deepest mantle. This is consistent with the case of lavas in Baffin Island, which have not only the highest ${ }^{3} \mathrm{He} /{ }^{4} \mathrm{He}$ isotopic ratios found so far (Starkey et al. 2009; Stuart et al. 2003), but also the lowest D/H ratio (Hallis et al. 2015).

\section{References}

Anderson DL (1998) The helium paradoxes. Proc Natl Acad Sci USA 95:4822-4827

Bouhifd MA, Jephcoat AP, Heber VS, Kelley SP (2013) Helium in Earth's early core. Nat Geosci 6:982-986

Class C, Goldstein SL (2005) Evolution of helium isotopes in the Earth's mantle. Nature 436:1107-1112
Demouchy S (2010) Diffusion of hydrogen in olivine grain boundaries and implications for the survival of water-rich zones in the Earth's mantle. Earth Planet Sci Lett 295:305-313

Gonnermann HM, Mukhopadhyay S (2007) Non-equilibrium degassing and a primordial source for helium in ocean-island volcanism. Nature 449:1037-1040

Hae R, Ohtani E, Kubo T, Koyama T, Utada H (2006) Hydrogen diffusivity in wadsleyite and water distribution in the mantle transition zone. Earth Planet Sci Lett 243:141-148

Hallis LJ, Huss GR, Nagashima K, Taylor GJ, Halldórsson SA, Hilton DR, Mottl MJ, Meech KJ (2015) Evidence for primordial water in Earth's deep mantle. Science 350:795-797

Hopp J, Trieloff M (2008) Helium deficit in high- ${ }^{3} \mathrm{He} /{ }^{4} \mathrm{He}$ parent magmas: predegassing fractionation, not a "helium paradox"". Geochem Geophys Geosyst. https://doi.org/10.1029/ 2007GC001833

Huang F, Chakraborty P, Lundstrom CC, Holmden C, Glessner JJG, Kieffer SW, Lesher CE (2010) Isotope fractionation in silicate melts by thermal diffusion. Nature 464:396-400

Kellogg LH, Turcotte DL (1987) Homogenization of the mantle by convective mixing and diffusion. Earth Planet Sci Lett $81: 371-378$

Kellogg LH, Turcotte DL (1990) Mixing and the distribution of heterogeneities in a chaotically convecting mantle. J Geophys Res Solid Earth Planets 95:421-432

Kurz MD, Jenkins WJ, Hart SR (1982) Helium isotopic systematics of oceanic islands and mantle heterogeneity. Nature 297:43-47

Labrosse S, Hernlund JW, Coltice N (2007) A crystallizing dense magma ocean at the base of the Earth's mantle. Nature 450:866-869

Li X, Liu Y (2015) A theoretical model of isotopic fractionation by thermal diffusion and its implementation on silicate melts. Geochim Cosmochim Acta 154:18-27

Moreira M (2013) Noble gas constraints on the origin and evolution of earth's volatiles. Geochem Perspect 2:229-403

Mukhopadhyay S, Parai R (2019) Noble gases: a record of earth's evolution and mantle dynamics. Annu Rev Earth Planet Sci 47:389-419 
Onions RK, Oxburgh ER (1983) Heat and helium in the Earth. Nature 306:429-431

Parman SW, Kurz MD, Hart SR, Grove TL (2005) Helium solubility in olivine and implications for high ${ }^{3} \mathrm{He} /{ }^{4} \mathrm{He}$ in ocean island basalts. Nature 437:1140-1143

Porcelli D, Halliday AN (2001) The core as a possible source of mantle helium. Earth Planet Sci Lett 192:45-56

Ricard Y (2015) 7.02-physics of mantle convection. In: Schubert G (ed) Treatise on geophysics, 2nd edn. Elsevier, Oxford, pp 23-71

Richter FM, Watson EB, Chaussidon M, Mendybaev R, Christensen JN, Qiu L (2014) Isotope fractionation of $\mathrm{Li}$ and $\mathrm{K}$ in silicate liquids by Soret diffusion. Geochim Cosmochim Acta 138:136-145

Shuster DL, Farley KA, Sisterson JM, Burnett DS (2004) Quantifying the diffusion kinetics and spatial distributions of radiogenic He-4 in minerals containing proton-induced He-3. Earth Planet Sci Lett 217:19-32

Starkey NA, Stuart FM, Ellam RM, Fitton JG, Basu S, Larsen LM (2009) Helium isotopes in early Iceland plume picrites: Constraints on the composition of high $\mathrm{He}-3 / \mathrm{He}-4$ mantle. Earth Planet Sci Lett 277:91-100

Stuart FM, Lass-Evans S, Godfrey Fitton J, Ellam RM (2003) High $3 \mathrm{He} / 4 \mathrm{He}$ ratios in picritic basalts from Baffin Island and the role of a mixed reservoir in mantle plumes. Nature 424:57-59

Walker D, Delong SE (1982) Soret separation of mid-ocean ridge basalt magma. Contrib Miner Petrol 79:231-240

Zhu H, Li X, Xu Y (2019) A helium stratified and ingassed lower mantle: resolving the helium paradoxes. Acta Geochim. https:// doi.org/10.1007/s11631-019-00378-2 